gel fluor..., hoặc với những răng có hố rãnh phức tạp có thể tiển hành trám bít hố rãnh để dự phòng sâu răng.

Nghiên cứu của chúng tôi cho kết quả với chỉ số sâu mất trám của nhóm đối tượng nghiên cứu là 5,09; ở mức cao theo phân loại của WHO (4,5$6,5)$. Trung bình mỗi người có 4,72 răng sâu; 0,04 răng mất do sâu; 0,33 răng sâu đã được trám. Trong đó chỉ số răng được trám $(T)$ thấp hơn nhiều so với chỉ số sâu răng (D), điều này phản ánh mức độ điều trị sâu răng còn chưa cao. Chỉ số DMFT ở giới nữ là 5,49 ở mức cao $(4,5-6,5)$ và giới nam là 4,38 ở mức trung bình $(2,7-4,4)$. Tuy nhiên có thể thấy rằng chỉ số sâu răng (D) ở nữ cao hơn ở nam còn chỉ số mất răng do sâu (M) và răng sâu được trám $(F)$ không có sự chênh lệch rõ ràng. So sánh với nghiên cứu của Ngô Thị Thu Hà [6], Hà Thị Nga [7], thấy rằng nghiên cứu này cũng cho chỉ số DMFT cao hơn và tập trung chủ yếu sự chênh lệch do cao hơn ở chỉ số sâu răng. Điều này có thể là do nghiên cứu của chúng tôi với cỡ mấu lớn hơn (770 sinh viên) và sử dụng tiêu chí đánh giá răng sâu theo phân loại ICDAS [4] còn tác giả sử dụng phân loại của WHO(1997) [1].

Chỉ số DMFT giảm dần từ khu vực 1 đến khu vực 3. Từ kiểm định thống kê cho thấy không có sự khác biệt có ý nghĩa giữa các khu vực sống. Điều này giống với một số nghiên cứu của Ngô Thị Thu Hà năm 2016 [6] Điều này có thể giải thích rằng đối tượng của nghiên cứu này đang ở lứa tuổi thanh thiếu niên với bộ răng vĩnh viễn và sự tích lũy sâu răng chưa đủ để gây ra sự khác biệt giữa các khu vực sống.

\section{KẾT LUÂNN}

Tỷ lệ sẩu răng của nhóm đối tượng nghiên cứu là $84,55 \%$ ở mức cao chủ yếu là sâu răng sớm. Trong đó tỷ lệ sâu răng ở nữ cao hơn ở nam, tỷ lệ sâu răng ở khu vực 1 cao hơn khu vực 2 và cao hơn khu vực 3 . Chỉ số DMFT của nhóm đối tượng nghiên cứu là 5,09, ở mức cao trong đó ở nữ cao hơn ở nam và khu vực 1 , khu vực 2 thì lớn hơn khu vực 3 . Từ kết quả nghiên cứu, những khuyến cáo và đề xuất có thể được đặt ra để gứi tới nhà trường và đối tượng nghiên cứu để có sự cải thiện và thay đổi tình trạng sâu răng.

\section{TÀI LIÊUU THAM KHẢO}

1. WHO (1997), Oral health survey, basic method,

2. Trân Văn Trường và CS (2001). Điêu tra sức khỏe răng miệng toàn quốc,. nhà xuất bản $Y$ học, 22-70.

3. Drachev, S. N., Brenn, T., \& Trovik, T. A. (2017), Dental caries experience and determinants in young adults of the Northern State Medical University, Arkhangelsk, North-West Russia,

4. Ismail Ai , Sohn $W$, Tellez M, Amaya A, Sen $A$, Hasson $\mathrm{H}$ et al. (2007). The International Caries Detection and Asseessment Syste (ICDAS): an integrated system for measuring dental caries. Community Dent Oral Epidemiol.

5. WHO (2013), Oral health survey, basic method, World Health Organization.

6. Ngô Thị Thu Hà (2016). Thực trang sâu răng, nhu câu điều trj và một số yếu tố ảnh hưởng tới bệnh sâu răng của sinh viên năm thứ nhất đại học Y Hà Nội năm học 2015-2016. trường đại học Y Hà Nội.

7. Hà Thị Nga (2015). Thực trạng sầu răng và liền quan giữa thói quen chăm sóc răng miệng với sâu răng của sinh viên $y 1$ trường đại học $Y$ Hà Nội năm học 2014-2015. trường đại học Y Hà Nội, 31-49.

\title{
KẾT QUẢ ĐIỀU TRỊ GÃY KÍN ĐẦU DƯớI XƯƠNG ĐÙI BÂNG NEP KHÓA Ở NGƯỜI TRƯỞNG THÀNH TẠI BỆNH VIÊ̂N TRUNG ƯƠNG THÁI NGUYÊN
}

\author{
TÓM TẮT.
}

Tạ Văn Công1, Trần Chiến ${ }^{1}$ Hoàng Văng Dung ${ }^{2}$, Nguyễn Ngọc Sơn ${ }^{2}$

Đặt vấn đề: Gãy đầu dưới xương đùi là một gãy xương lớn, phức tạp, thường ảnh hưởng đến chức năng vận động của khớp gối. Nepp khóa đầu dưới xương đ̛̣ùi giúp cố định vững chắc ổ gãy theo cấu trúc giải phẩu, bệnh nhân tập vận động sớm șau mổ. Mưc tiêu nghiên cứu: Đánh giá kết quả phẫu thuật điểu trị gãy kín đầu dưới xương đùi bằng nẹp khóa ở người trưởing thành. Đối tượng và phương pháp nghiên cứu: Nghiên cứu mô tả cắt ngang. Từ tháng 1 năm 2018 đển tháng 6 năm 2021, 33 bệnh nhân trong độ tuổi từ 18 tuổi trở lên gãy kín đầu dưới xương đưi được phẫu thuật kết hợp xương bằng nẹp khóa. Thời 
gian theo dõi 6 tháng. Kết quả: Trong 33 bệnh nhân nghiên cứu có $12(36.4 \%)$ bệnh nhân nam và 21 (63.6\%) bệnh nhân nữ. Kết quả $100 \%$ bệnh nhân liền xương. Kết quả nắn chỉnh ổ gãy trên Xquang theo Larson - Bostman: Rất tốt: 97.0\%, tốt: 3.0\%. Biên độ vận động khớp gối: 54,5\% gấp gối $\geq 125^{\circ}, 24.2 \%$ gấp gối từ $100^{\circ}-124^{0}, 15.2 \%$ gấp gối $90^{\circ}-99^{\circ}, 6.0 \%$ gấp gối $<90^{\circ}$. Kết quả phục hồi chức năng theo Sanders. R: rất tốt: $63.8 \%$, tốt: $18.2 \%$, trung bình $12.1 \%$ và kém là $3.0 \%$. Kết luận: Điêu trị gãy kín đầu dưới xương đùi bằng nẹp khóa mang lại kết quả khả quan, thích hợp với các loại gãy xương đầu dưới xương đùi, hiện là lưa chon tối ưu cho loai gãy này. khóa.

Tư khóa: Gãy đâuu dưới xương đùi, kết xương nẹp

\section{SUMMARY}

\section{RESULTS OF TREATMENT OF DISTAL FEMUR FRACTURES BY LOCKING PLATE FIXATION IN ADULTS AT THAI NGUYEN NATIONAL HOSPITAL}

Background: Distal femur fractures are a large, complex fractures, which often affects to the motor function of the knee. The locking compression plates for distal femur helps firmly fix the fracture, early rehabilitation. Objectives: Assessing results of treatment of distal femur fractures by locking plate fixation in adults. Subjects and method: Cross sectional description. From January 2018 to June 2021, 33 patients, from 18 years old and older with distal femur fracture, were treated by locking plate fixation and observed for at least 6 months- follow up. Results: There were $12(36.4 \%)$ males and 21 $(63.6 \%)$ females. The rate of bone union was $100 \%$. Results of fracture correction on X-ray by Larson Bostman: Excellent: $97.0 \%$, good: $3.0 \%$. Range of knee motion: $54.5 \%$ achieved a complete flexion $\geq$ $125^{\circ}, 24.2 \%$ range $100^{\circ}-124^{\circ}, 15.2 \%$ range $90^{\circ}-$ $99^{\circ}, 6 \%$ knee flexion $<90^{\circ}$. Results of rehabilitation by Sanders.R: excellent: $63.8 \%$, good: $18.5 \%$, average: $12.1 \%$ and poor $3.0 \%$. Conclusion: Results of treatment of distal femur fractures by locking plate is very positive, including older patients with osteoporosis, which is now the optimal treatment choice for this type of fracture.

Key words: Distal femur fracture, locking plate fixation.

\section{I. ĐẶT VẤN ĐỀ}

Gãy đầu dưới xương đùi là gãy tại vùng chuyển tiếp giữa vùng hành xương và thân xương ở $1 / 3$ dưới của xương đùi thuộc loại gãy trên lồi cầu hoặc liên lồi câu xương đùi, đường gãy có thể kéo dài lên $1 / 3$ giữa xương đùi hay có đường gãy phạm khớp, chiếm dưới $1 \%$ tổng số ca gãy xương và khoảng 3 đến $6 \%$ tổng số ca gãy xương đùi. [5], [7], [8]. Gãy xương vùng này ảnh hưởng rất lớn đến diện khớp và tầm vận động của khớp gối, vì vậy việc điều trị đòi hỏi cần nắn chỉnh tốt về mặt giải phẫu, phục hồi diện khớp, cỗ định vững chắc ổ gãy giúp bệnh nhân tập vận động sớm tránh để lại di chứng về sau như: teo cớ, cứng khớp gối.

Có nhiều phương pháp điều trị gãy kín đầu dưới xương đùi như: kéo nắn bó bột, phẫu thuật kết hợp xương nẹp vít, nẹp góc, nẹp DCS, nẹp ốp lồi cầu...[4], [6]. Hiện nay, nẹp khóa được áp dụng phổ biến, nẹp khóa giúp cố định vững chắc ổ gãy, phục hồi tốt về mặt giải phẫu tạo điêu kiện cho bệnh nhân tập vận động phục hồi chức năng sớm sau mổ.

Tại Bệnh viện Trung ương Thái Nguyên, nẹp khóa đâu dưới xương đùi đã được sử dụng trong nhiều năm, tuy nhiên chưa có nghiên cứu đánh giá về kết quả của phương pháp để có thể đưa ra những rút ra những bài học kinh nghiệm nhằm mang lại hiệu quả điều trị tối ưu cho người bệnh. Vì vậy, chúng tôi tiến hành nghiên cứu này với mục tiều: Đánh giá kết quả phẫu thuật điều tri gãy kín đầu dưới xương đùi ở người trưởng thành bằng nẹp khóa.

\section{II. ĐỐI TƯỢNG VÀ PHƯƠNG PHÁP NGHIÊN CỨU}

1. Đối tượng nghiên cứu. Gồm những bênh nhân từ 18 tuổi trở lên bị gãy kín đầu dưới xương đùi do chấn thương được điều trị phẫu thuât kết hợp xương bằng nẹp khóa tại khoa Chấn thương chỉnh hình - Bệnh viện Trung ương Thái Nguyên từ tháng 1 năm 2018 đến tháng 3 năm 2021.

*Tiêu chuẩn lựa chọn

- Bệnh nhân $\geq 18$ tuổi được chẩn đoán gãy kín đầu dưới xương đùi, được điều trị phẫu thuật kết hợp xương bằng nẹp khóa

- Các bệnh nhân có đủ hồ sơ bệnh án và đồng ý tham gia nghiên cứu. Có phim X Quang trước và sau phẫu thuật.

*Tiêu chuẩn loại trừ

- Gãy xương bệnh lý

- Gãy kín đầu dưới xương đùi có tổn thương bó mach khoeo.

- Bệnh nhân có chống chỉ định phẫu thuật do những bệnh lý nội khoa kèm.

\section{Phương pháp nghiên cứu}

- Phương pháp nghiên cứu: phương pháp mô tả cắt ngang

- Cõ̃ mẫu và chọn mẫu:

+ Cỡ mẫu: mẫu toàn bộ

+ Phương pháp chon mẫu: Chọn mẫu thuân tiện: Chọn tất cả những bệnh nhân đủ tiểu chuẩn trong thời gian nghiên cứu.

- Nội dung nghiên cứu:

+ Đặc điểm đối tượng nghiên cứu theo tuổi và giới 
+ Phân loại gãy đầu dưới xương đùi theo AO/ASIF

+ Đánh giá kết quả nắn chỉnh ổ gãy trên Xquang theo Larson - Bostman

+ Kết quả liền xương sau 6 tháng

+ Biên độ vận động gấp gối
+ Đánh giá kết quả phục hồi chức năng theo Sanders R (1991)

- Xử lý số liệu bằng phần mềm SPSS 20.0

\section{KẾT QUẢ NGHIÊN CỨU}

\section{1. Đặc điểm của đối tượng nghiên cứu}

*Tuổi và giới

Bảng 1: Phân bố bệnh nhân theo tuổi và giới

\begin{tabular}{|c|c|c|c|c|c|c|}
\hline \multirow{2}{*}{ Độ tuổi } & \multicolumn{2}{c|}{ Naới } & \multicolumn{2}{c|}{ Nữ } & \multicolumn{2}{c|}{ Tống } \\
\cline { 2 - 7 } & Số BN & Tỷ lệ (\%) & Số BN & Tỷ lệ (\%) & Số BN & Tỷ lệ (\%) \\
\hline $18-60$ & 11 & 33,3 & 7 & 21,2 & 18 & 54,5 \\
\hline$>60$ & 1 & 3 & 14 & 42,4 & 15 & 45,5 \\
\hline Tống & $\mathbf{1 2}$ & $\mathbf{3 6 , 4}$ & $\mathbf{2 1}$ & $\mathbf{6 3 , 6}$ & $\mathbf{3 3}$ & $\mathbf{1 0 0}$ \\
\hline
\end{tabular}

Có $12(36.4 \%)$ bệnh nhân nam và $21(63.6 \%)$ bệnh nhân nữ. Trong đó nhóm nữ ở độ tuổi $>60$ tuổi chiếm tỷ lệ cao nhất với 14 bệnh nhân (chiếm 42.4\%)

*Phân loại gãy xương theo AO/ASIF

Bảng 2: Phân loại gãy đầu dưới xương đùi theo AO/ASIF

\begin{tabular}{|c|c|c|c|}
\hline \multicolumn{2}{|c|}{ Phân loại } & Số bệnh nhân & Tỷ lệ (\%) \\
\hline \multirow{3}{*}{ Nhóm } & A1 & 12 & 36,4 \\
\cline { 2 - 4 }$A$ & $\mathrm{~A} 2$ & 9 & 27,3 \\
\cline { 2 - 4 } & $\mathrm{A} 3$ & 1 & 3 \\
\cline { 2 - 4 } & Cộng & 22 & 66.7 \\
\hline \multirow{3}{*}{ Nhóm } & $\mathrm{B} 1$ & 2 & 6.1 \\
\cline { 2 - 4 } $\mathrm{B}$ & $\mathrm{B} 2$ & 0 & 0 \\
\cline { 2 - 4 } & $\mathrm{B} 3$ & 0 & 0 \\
\cline { 2 - 4 } & Cộng & 2 & 6.1 \\
\hline \multirow{3}{*}{ Nhóm } & C1 & 2 & 6,1 \\
\cline { 2 - 4 } C & $\mathrm{C} 2$ & 7 & 0 \\
\cline { 2 - 4 } & $\mathrm{C} 3$ & 0 & 27.3 \\
\cline { 2 - 4 } & Cộng & 9 & \\
\hline
\end{tabular}

Nhóm gãy trên lồi cầu (nhóm $A$ ) chiếm tỷ lệ cao nhất với 22 bệnh nhân (chiếm 66.7\%), gãy liên liôi cầu 9 bệnh nhân (chiếm 27.3\%)

\section{Kết quả sau phẫu thuật}

* Kết quả nắn chỉnh ổ gãy trên Xquang sau phẫu thuật theo Larson - Bostman. Tất cả các bệnh nhân trong nghiên cứu đều có kết quả nắn chỉnh ổ gãy trên Xquang theo Larson Bostman đạt kết quả rất tốt (32/33 - 97.0\%) và tốt $(1 / 33-3.0 \%)$

*Kết quả liền xương sau 6 tháng: 100\% bệnh nhân đạt kết quả liền xương sau 6 tháng, không có bệnh nhân khớp giả

* Kết quả phục hồi chức năng

Bảng 3: Biên độ vận động gấp gối

\begin{tabular}{|c|c|c|}
\hline $\begin{array}{c}\text { Biên độ gấp } \\
\text { gối }\end{array}$ & $\begin{array}{c}\text { Số bệ̂nh } \\
\text { nhẩn }\end{array}$ & Tỷ lệ (\%) \\
\hline Trên $125^{\circ}$ & 18 & 54.5 \\
\hline $100-124^{\circ}$ & 8 & 24.2 \\
\hline $90-99^{\circ}$ & 5 & 15.2 \\
\hline Dưới $90^{\circ}$ & 2 & 6.0 \\
\hline Tống & $\mathbf{3 3}$ & $\mathbf{1 0 0}$ \\
\hline
\end{tabular}

Có 18 bệnh nhân (54.5\%) đạt biên độ vận động gấp gối $\geq 125^{\circ}, 8$ bệnh nhẩn (24.2\%) gấp gối từ $100^{\circ}-124^{\circ}, 6$ bệnh nhân $(15.2 \%)$ từ $90^{\circ}$ $-99^{\circ}, 2$ bệnh nhân (6.0\%) gấp gối $<90^{\circ}$.

Bảng 4: Kết quả phục hồi chức năng theo Sander R (1991)

\begin{tabular}{|l|l|}
\hline Kết quả PHCN Số bệnh nhân & Tỷ lệ (\%) \\
\hline
\end{tabular}

\begin{tabular}{|c|c|c|}
\hline Rất tốt & 21 & 63.6 \\
\hline Tốt & 6 & 18.2 \\
\hline Trung bình & 4 & 12.1 \\
\hline Kém & 2 & 6.0 \\
\hline Tống & $\mathbf{3 3}$ & $\mathbf{1 0 0}$ \\
\hline
\end{tabular}

Kết quả PHCN theo Sander R: Rất tốt có 21 bệnh nhân $(63.6 \%)$, tốt có $6(18.2 \%)$, trung bình có 4 (12.1\%), kém 2 BN $(6.0 \%)$

\section{*Hình ảnh ca lâm làng}
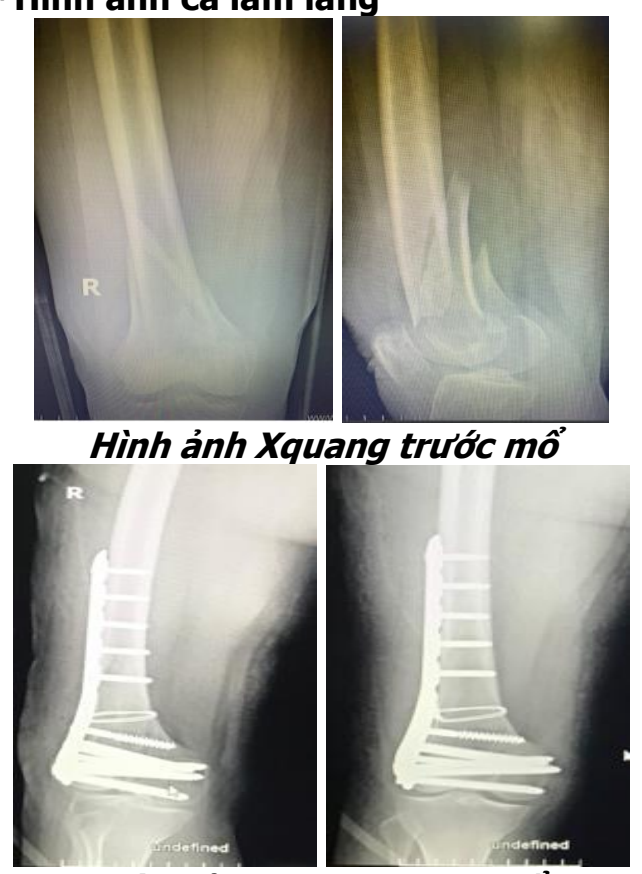

Hình ảnh Xquang sau mố 


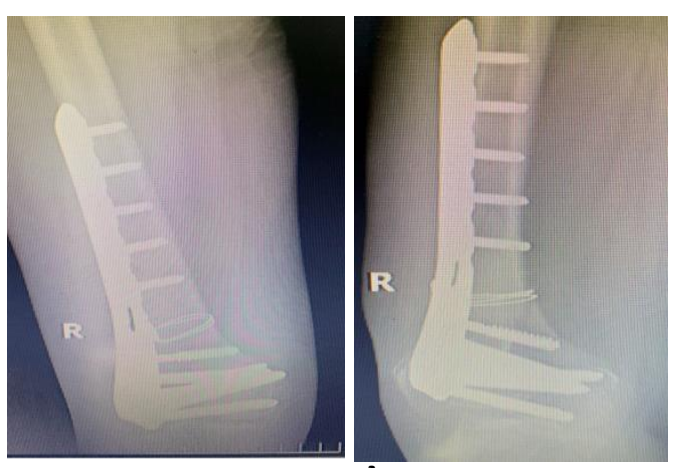

Hình ảnh Xquang kiểm tra sau 6 tháng

\section{BÀN LUÂN}

Trong nghiên cứu của chúng tôi, có $12 / 33$ (36.4\%) bệnh nhân nam và 21/33 (63.6\%) bệnh nhân nữ 18/33 (54.5\%), tỷ lệ bệnh nhân nam ở độ tuổi từ 18 - 60 tuổi chiểm chủ yếu với $33.0 \%$, tỷ lệ bênh nhân nữ chiếm tỷ lệ cao ở độ tuổi > 60 tuổi với 42.4\%. Kết quả này cho thấy gãy đầu dưới xương đùi gặp nhiêu hơn ở nam giới trong độ tuổi lao động còn ở độ tuổi sau tuổi lao động gặp nhiều ở nữ giới. Sự khác biệt này có liên quan đến nguyên nhân chấn thương, thường gặp do chấn thương năng lượng cao như: tai nạn giao thông, tai nạn lao động ở nhóm người trong độ tuổi lao động và hay gặp do tai nạn sinh hoạt ở nhóm tuổi cao, chất lượng xương kém, năng lượng chấn thương thấp. Kết quả này có sự khác biệt về tỷ lệ nam và nữa so với với nghiển cứu của các tác giả Martinet.O (51.5\% nam và 48.5\% nữ)[5], Hoàng Ngọc Minh (48.15\% nam và $51.85 \%$ nữ) [4], Đinh Trung Hiếu (56\% nam và $44 \%$ nữ)[1]. Nguyêen nhân của sự khác biệt này có thể do cỡ mẫu nghiên cứu của chúng tồi chưa đủ lớn và không đại diện cho quần thể.

Các bệnh nhân thuộc nhóm gãy $A$ là chủ yếu với $22 / 33$ BN $(66.7 \%)$, đây là loại gãy trên lồi cầu, là vùng chuyển tiếp giữa thân xương đùi và phần xương xốp đầu dưới xương đùi, do đó vùng này thường yếu và dễ tổn thương khi có lực tác động vào, đặc biệt là trên những bệnh nhẩn lớn tuổi có chất lượng xương kém.

Kết quả nắn chỉnh ổ gãy có $32 / 33 \mathrm{BN}$ (97.0\%) đạt kết quả rất tốt, hết di lệch, $1 / 33 \mathrm{BN}$ đạt tốt, di lệch ít. Các bệnh nhân thuộc nhóm gã̃y $A$ là chủ yếu, ổ gãy thường không phức tạp, thuận lợi cho quá trình nắn chỉnh về giải phẩu trong mổ, nẹp khóa giúp cố định vững chắc ổ gãy sau nắn chỉnh vì vậy cho kết quả nắn chỉnh tốt sau mổ. Kết quả ngày tương đương với kết quả nghiên cứu của Hoàng Ngọc Minh (Rất tốt: 92.59\%, tốt 7.41\%)[4], Ngô Quốc Hoàn (rất tốt và tốt: $95.8 \%)[2]$
Kết quả liền xương: $100 \%$ bện nhân liền xương sau 6 tháng. Kết quả này tương đương với kết quả nghiên cứu của Đinh Trung Hiếu $(98.0 \%)$ [1] và Ngô Quốc Hoàn (95.2\%) [2]. Vùng đầu dưới xương đùi giàu mạch nuôi, là vùng chuyển tiếp giữa xương cứng và xương xốp nên dễ liền xương, nẹp khóa đầu dưới xương đùi giúp cố định vững chắc ổ gãy tạo điều kiện cho quá trình liền xương diễn ra thuận lợi.

Biên độ gấp gối: $18 \mathrm{BN}(54.5 \%)$ đạt biên độ vận động gấp gối $\geq 125^{\circ}, 8 \mathrm{BN}(24.2 \%)$ gấp gối từ $100^{\circ}-124^{\circ}, 5 \mathrm{BN}(15.2 \%)$ từ $90^{\circ}-99^{\circ}, 2$ $(6.0 \%)$ bệnh nhân hạn chế gấp gối $<90^{\circ}$, kết quả này tương đương với nghiên cứu của Hoàng Ngọc Minh (57.89\% gấp gối $\geq 125^{\circ}$ và không có bệnh nhân nào hạn chế gấp gối $<90^{\circ}$ )[4], Campana (47.2\% gẩp gối $\geq 130^{\circ}, 30.6 \%$ gấp gối $100^{\circ}-129^{\circ}, 5.5 \%$ hạn chế gấp gối $<80^{\circ}$ )[8]

Kết quả PHCN theo Sander R: Rất tốt có 21 BN $(63.6 \%)$, tốt có $6(18.2 \%)$, trung bình có 4 $(12.1 \%)$, kém $2 \mathrm{BN}(6.0 \%)$, kết quả này cho thấy khả năng cố định vững chắc ổ gãy của nẹp khóa đầu dưới xương đùi, cho phép bệnh nhẩn tập vận động sớm sau phẫu thuật, mang lại kết quả phục hồi chức năng cao. Kết quả này tương đương với kết quả trong nghiên cứu của Hoàng Ngọc Minh (rất tốt $57.89 \%$, tốt 31.58\%, trung bình 10.53\%)[4], Trương Trí Hữu (rất tốt 76.5\%, tốt 14.7\%, trung bình 2.9\%) [3]

\section{KẾT LUÂNN}

Nẹp khóa đầu dưới xương đùi có thể áp dụng cho tất cả các loại gãy đầu dưới xương đùi, bao gồm cả những bệnh nhân lớn tuổi loãng xương, nẹp khóa giúp cố định vững chắc ổ gãy, kể cả những ổ gãy phức tạp bởi tính ưu việt của nó, từ đó giúp bệnh nhân vận động sớm sau mổ, hạn chế được các di chứng.

Sử dụng nẹp khóa trong điều trị gãy kín đầu dưới xương đưi cho kết quả cao: $100 \%$ bệnh nhân liền xương sau 6 tháng, kết quả phục hồi chức năng theo Sander rất tốt và tốt đạt $81.8 \%$.

\section{TÀI LIẸU THAM KHẢO}

1. Đinh Trung Hiếu, Đàm Văn Cương (2018). "Kết quả điều trị gãy kín đầu dưới xương đưi bằng nep vít khóa tại Bệnh viện đa khoa Trung Ương Cẩn tho". Tapp chí y dược học Cần Thơ, Số 16, 1-7.

2. Ngô Quốc Hoàn , Mỵ Duy Tiến, Nguyễn Đức Thọ , et al (2019). "Đánh giá kêt quá ban đâu điều trí gãy kín đâu dưới xương đưi bằng phẫu thuật kết xương nẹp khóa". Tạp chí y dược học thực hành, 175 (22), 75-84.

3. Trương Trí Hữu, Nguyễn Thanh Huy (2015). "Kết quả bước đầu phấu thuật kết xương gãy đâu dưới xương đùi bằng nẹp vít khóa". Y Học TP Hồ Chí Minh Tập 19 (Số 1), 67 - 72. 
4. Hoàng Ngoc Minh (2020). "Nghiên cứu khả năng cố định ổ gãy trên thực nghiệm và kết quả điêu trị gãy kín đâuu dưới xướng đưi nìười lớn bằng nẹp khóa". Luận án Tiến sĩ y học, Học Viện Quân Y.

5. Martinet $O$, Cordey J, Harder Y, et al (2000). "The epidemiology of fractures of the distal femur". Injury, 31 Suppl 3, C62-63.

6. Chapman W.M. (1993). "Supracondylar and articular fractures of the distal femur". Operative orthopaedics, 1, $651-661$.

7. Coon M.S, Best B.J (2021). "Distal Femur Fractures". Treasure Island (FL): StatPearls Publishing.

8. Campana V, Ciolli G, Cazzato G, et al (2020). "Treatment of distal femur fractures with VA-LCP condylar plate: A single trauma centre experience". Injury, 51 Suppl 3, S39-S44.

\title{
VAI TRÒ CỦA ĐO ẢNH ĐộNG NHÃN Đồ (VNG) TRONG CHẨN ĐOÁN RỐI LOẠN TIỀN ĐÌNH
}

\author{
Lê Minh Kỳ*,**, Đồng Thị Như Quỳnh**, Trần Phương Thanh**, \\ Đoàn Việt Cường**, Dương Đình Lương**, Nguyễn Thị Tố Uyên***.
}

\section{TÓM TẮT}

Chóng mặt là một rối loạn thường gặp, bệnh nhân bị chóng măt có thế tới khám và điều tri ở các chuyên khoa khác nhau như nội thần kinh, lão khoa, nội khoa, tai mũi họng... Mỗi chuyên khoa lại có tiếp cận khác nhau trong chẩn đoán, xét nghiệm thăm dò thường làm nhất là chup CT và MRI sọ não. Tuy vậy đôi khi vẫn bỏ sót nhiểu chẩn đoán nguyên nhân. Hê thống VNG có thể ghi lại và lượng giá được hệ thổng vận đông nhãn câu và phản xa tiền đành mắt (VOR). Chúng tôi sử dụng bộ test đánh giá tiền đình gồm VNG và vHIT và thăm dò thính học để sàng lọc và phân loại nguyên nhân rối loạn tiền đình, chụp CT hoăc MRI so não nếu cần. Mục tiêu nghiên cứu nhằm phẩn loại các nguyên nhân gầy rối loạn tiền đình đến khám tại phòng khám TMH dựa trên bồ test đánh giá. Đối tượng và phương pháp nghiên cứu: 668 bệnh nhân đển khám vì chóng măt tai phòng khám TMH BV đa khoa Tâm Anh Hà Nội từ tháng 11/2018 đến tháng 7/2019. Tất cả bệnh nhân đều được khám lâm sàng, làm các nghiệm pháp tiền đình đơn giản và được đánh giá bằng bộ test trên hệ thống VNG, vHIT (Interacoustic), các thăm dò thính học như đo thính lực đơn âm, nhĩ lượng. Kết quả: Rối loạn tiền đình do nguyên nhân trung ương chiếm 55,9\%, chóng mặt do rối loạn tiền đình ngoại biên có chiếm $63,9 \%$. Trong số các nguyên nhân ngoai biên, BPPV (Bênh thach nhî lạc chỗ) chiếm nhiều nhất với tỷ lệ $66,5 \%$; Sau đó là Bênh Meniere chiếm 27,6\%; Viêm thần kinh tiền đình chiếm $22,2 \%$. Bệnh thạch nhĩ lạc chỗ ống bán khuyên sau chiếm đa số $83,5 \%$, ống bán khuyên ngang $26,8 \%$ và ống bán khuyên trước 14,8\%. Bệnh thạch nhî lac chố cả hai bên đồng thời chiếm 33,5\%. Kết luận: Bộ test thăm dò chức năng tiền đình VNG, vHIT, thắm dò thính học là một thăm dò cân thiết

*Đai hoc QG Hà Nọi (VNU)

**Bệnh viện Đa khoa Tâm Anh Hà Nội

***Đai hoc Y Hà Nôi

Chịu trách nhiệm chính: Lê Minh Kỳ

Email: leminhky.ent@gmail.com

Ngày nhận bài: 13.9.2021

Ngày phản biên khoa hoc: 8.11.2021

Ngày duyệt bài: 16.11.2021 trong chẩn đoán nguyên nhân rối loan thăng bằng chóng mặt, cung cấp các dữ liệu khách quan, tin cậy trong xác lấp chẩn đoán nguyên nhân.

Tư khóa: VNG, vHIT, thính lực đồ.

\section{SUMMARY}

\section{ROLE OF VNG - vHIT IN THE DIAGNOSTIC} OF VESTIBULAR DISORDER

Dizzy or vestibular disorder patients frequently present in neurology, geriatric, general medicine and ENT clinics... and individual specialties may develop a strategy for evaluating symptoms of disequilibrium in their own particular area of expertise, but may either overlook the many causes of dizziness arising in other systems. The aim of this study was to evaluate the role of VNG, VHHIT and audiological test as a useful tool in evaluating patients with vertigo, to confirm the level of lesion in a patient with vertigo, to differentiate between central and peripheral causes of vertigo and to identify the cause of peripheral vertigo. Patients and method: This is a prospective descriptive study on 668 patients with dizziness or vertigo consulted at ENT Depart, Tam Anh hospital Hanoi from 2018 Nov to 2019, Jul. All patients have been investigated by the battery test included VNG, vHIT and audiological test. Results: 668 patients were included in the analysis (259 men (38,8\%), 409 woman $(61,2 \%)$, the peak of age interval was $50-59$ years old. The most frequently diagnosed peripheral disorders diseases were: benign paroxysmal positional vertigo, Ménière syndrome and vestibular neuritis. In $83,5 \%$ of cases, mainly affected was the posterior semicircular canal, in $26,8 \%$ of the patients - the horizontal semicircular canal, 95 patients $(35,5 \%)$ having bilateral canals simultaneously involved. Conclusions: Testing of the vestibulo-ocular through videonystagmography and vHIT, tonal vocal audiometry are important for a positive diagnosis and etiological differentiation of vestibular syndromes.

Keywords; video Head Impulse Test (vHIT), videonystagmography, audiogramme.

\section{I. ĐẶT VẤN ĐỀ}

Chóng mặt khá phổ biến trong đời sống 